\title{
Association between computed tomography-detected calcification and thyroid carcinoma
}

\author{
W. LIU ${ }^{\ddagger}$ X. Y. DONG ${ }^{\ddagger}$, C. S. ZHU, J. YANG*, J. YANG, K. W. SHAO, L. X. YUAN, H. R. CHEN, W. LU, Y. ZHU \\ Radiology Department, ShangHai TongRen Hospital, ShangHai 200336, China \\ ${ }^{*}$ Correspondence: junyangdr@163.com \\ ${ }^{*}$ Contributed equally to this work.
}

Received July 28, 2014 / Accepted February 18, 2015

\begin{abstract}
This study aimed to investigate the diagnostic value of calcification detected by computed tomography (CT) for the differentiation of benign and malignant thyroid nodules. This is a retrospective study of 930 consecutive patients (709 women, 221 men; mean age 51 years) with pathologically proven thyroid nodules. The characteristics of calcification on CT images were correlated with the pathological results. A total of 168 patients were pathologically diagnosed with thyroid carcinomas and 762 patients with benign thyroid nodules. Calcification was found in 231 cases $(24.84 \%)$. The incidence of calcification was significantly higher in patients with thyroid carcinoma $(52.38 \%)$ than in those with benign nodules $(18.77 \% ; P<0.001)$. Detection of calcification in diagnosing thyroid carcinoma had a sensitivity of $52.38 \%$ (88/168) and specificity of $81.23 \%$ (619/762). No significant difference was noticed in the incidence of microcalcification $(\leq 2 \mathrm{~mm})$ between malignant and benign nodules $(P=0.305)$. Calcification is more frequently found in thyroid carcinomas than benign nodules. CT detected-calcification may suggest malignant disease. Further confirmation of the suspected malignancy with fine-needle aspiration or surgery is still needed.
\end{abstract}

Key words: thyroid neoplasm, thyroid nodule, calcinosis, computed tomography

Thyroid neoplasm include nodular goiter, thyroid adenoma, and thyroid carcinoma. Differentiating between benign and malignant thyroid nodules can be tricky with clinical manifestation and image findings. Calcification is a common finding in thyroid imaging, and can occur in both benign and malignant thyroid lesions [1-4]. It has been found that the thyroid carcinoma has a higher incidence of calcification than benign thyroid nodules $[5,6]$. Most of these calcified thyroid nodules were detected with ultrasonography. However, computed tomography (CT) detected-calcification has rarely reported [7]. Here we report our results with an increased sample size compared with Wu et al [7] (930 vs. 383).

In this study, we retrospectively reviewed 930 patients with thyroid nodules that underwent thyroidectomy and pathological examination. The calcification pattern, size, and location were analyzed and correlated with the pathology of the thyroid nodules.

\section{Patients and methods}

Patients. From January 2005 to November 2013, 930 patients with thyroid nodules underwent thyroidectomy in our hospital. The diagnosis was made pathologically. The patients included 221 men and 709 women (man: woman ratio, 1:3.2). Their ages ranged from 13 to 82 years with a median age of 51 years. The initial symptom in most patients was goiter with disease courses from 2 days to 6 years. This study was approved by the Ethics Committee of our hospital.

Imaging study. CT images were obtained with the patients in the prone position with hyperextension of the neck (GE BrightSpeed, LightSpeed, 32 slice). The slice thickness and interslice interval were both 3 to $5 \mathrm{~mm}$. Plain and enhanced scanning was performed from the upper borderline of the hyoid gland to the aortic arch. The contrast was OMNIPAQE $(300 \mathrm{mg} / \mathrm{ml}) 80-100 \mathrm{ml}$ injected via the ulnar vein at a rate of 2-3 $\mathrm{ml} / \mathrm{s}$. Dual-phase enhanced scanning was performed at $35 \mathrm{~s}$ and $50 \mathrm{~s}$ after contrast injection. The CT images were interpreted independently by two experienced radiologists. When different opinions occurred, the two readers discussed to reach agreement.

Classification of the calcification. Microcalcification has a diameter $\leq 2 \mathrm{~mm}$. Coarse calcification has a diameter $>2 \mathrm{~mm}$ or irregular eggshell calcification. Only one calcification was solitary and $>1$ calcification was multiple. The calcification 

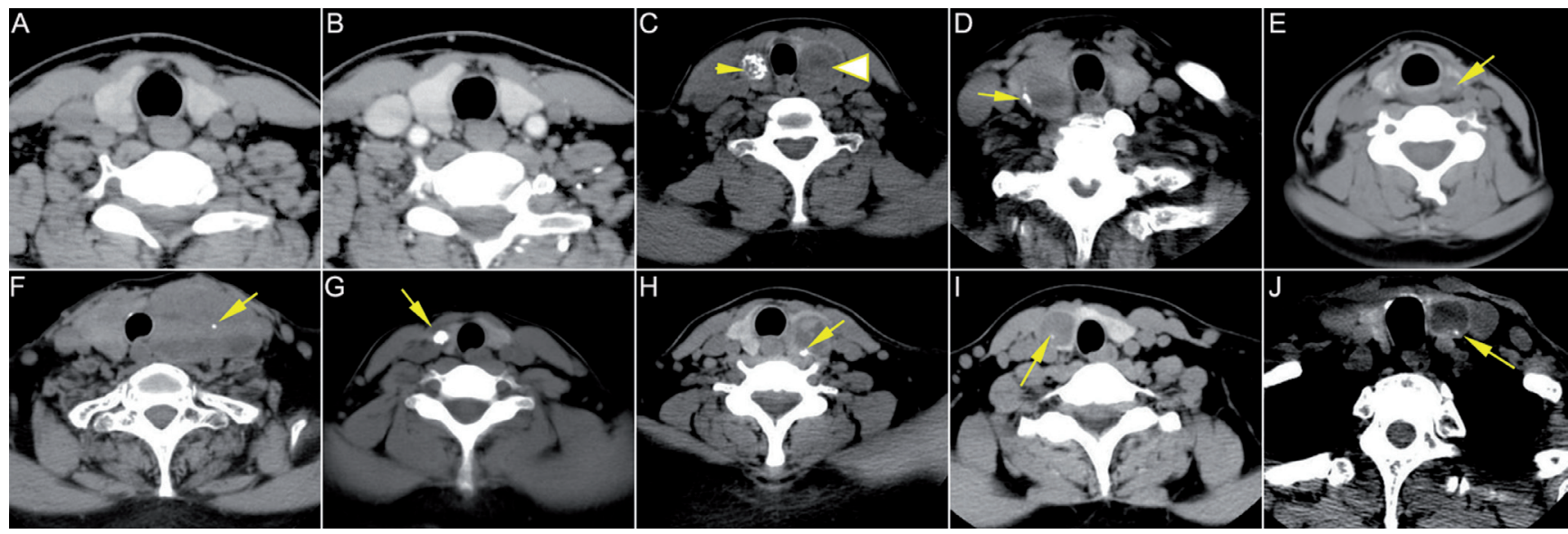

Figure 1. CT images of the thyroid nodules.

A) The thyroid CT image of a healthy patient in the plain scanning. B) The thyroid CT image of a healthy patient in the enhanced scanning. C) Calcification (arrow) was noticed in the right thyroid, which was pathologically diagnosed as papillary carcinoma. A cyst (arrow head) was found in the left thyroid, with a pathological result of follicular adenoma. D) CT detected coarse calcification (arrow) in the right side, which was pathologically diagnosed as nodular goiter with lymphocyte infiltration. E) CT detected microcalcification (arrow) in the left thyroid with a pathological result of papillary carcinoma. F) CT showed bilateral thyroid goiter and left-sided calcification (arrow). Pathological examination found adenoma with calcification. G) A CT-detected right-sided coarse calcification (arrow) was pathologically diagnosed as microcarcinoma. $\mathrm{H}$ ) CT detected a coarse calcification in the left thyroid (arrow), which was shown by pathological examination as follicular adenoma with calcification. I) A microcalcification (arrow) in the right thyroid detected by CT was shown by pathological examination as papillary carcinoma. J) CT found left-sided peripheral calcification (arrow), which was pathologically proven to be adenoma with calcification.

was also classified as intranodular calcification and peripheral calcification. The diagnosis of nodular goiter did not exclude thyroid adenoma. The diagnosis of thyroid adenoma included follicular adenoma and acidophilic adenoma. The diagnosis of Hashimoto thyroiditis did not exclude nodular goiter and adenoma.

Statistical analysis. The data were analyzed using SPSS software (SPSS 21.0, IBM, US). The comparisons were made with $\chi^{2}$ test and $\mathrm{P}<0.01$ was considered statistically significant.

\section{Results}

Pathological results. Of all the cases, 18.06\% (168/930) were malignant thyroid nodules and $81.94 \%$ (762/930) were

Table 1. Pathological diagnosis of the thyroid nodules

\begin{tabular}{lc}
\hline Pathology & Values (n, \%) \\
\hline Malignant thyroid nodules & $168(18.06 \%)$ \\
Papillary carcinoma & $92(54.76 \%)$ \\
Follicular carcinoma & $7(4.17 \%)$ \\
Medullary carcinoma & $6(3.57 \%)$ \\
Microcarcinoma & $63(37.50 \%)$ \\
Benign thyroid nodules & $762(81.94 \%)$ \\
Nodular goiter & $293(38.45 \%)$ \\
Thyroid adenoma & $402(52.76 \%)$ \\
Hashimoto thyroiditis & $62(8.14 \%)$ \\
Subacute thyroiditis & $5(0.65 \%)$ \\
\hline
\end{tabular}

benign thyroid nodules. Among the 168 malignant cases, 91 patients had papillary carcinomas, 7 had follicular carcinomas, 6 had medullary carcinomas, and 63 had microcarcinomas. The 762 benign cases contained 293 nodular goiter cases, 402 cases of thyroid adenoma, 62 cases of Hashimoto thyroiditis and 5 cases of subacute thyroiditis (Table 1). Besides, in 66.67\% of the patients with thyroid carcinoma, benign nodules were also found, including 40 cases of nodular goiter, 41 cases of adenoma, and 31 cases of Hashimoto thyroiditis (Fig. 1). Metastases to the neck lymph nodes were seen in 6 cases of thyroid carcinoma.

Calcification detected by CT. Calcification was found in 231 cases of all patients (24.84\%). The incidence of calcification was significantly higher in patients with thyroid carcinoma than those with benign nodules $(52.38 \%$ vs $18.77 \% ; P<0.001)$ (Table 2). In patients with calcified nodules, no significant differences in the incidences of microcalcification $(\leq 2 \mathrm{~mm})(P=$ $0.31)$ and solitary calcification $(P=0.46)$ were noticed (Table $2)$. However, the incidence of intranodular calcification was significantly higher in patients with thyroid carcinoma than those with benign nodules $(P<0.01)$ (Table 2$)$, with a sensitivity of $79.55 \%$ and a specificity of $67.83 \%$. In patients with various malignant thyroid nodules, no significant difference was found between the incidence of microcalcification and coarse calcification (Table 3 ).

Sex and age relationships with thyroid nodules. The incidence of thyroid carcinoma did not differ significantly between males and females $(P>0.05)$. In patients with either benign or malignant thyroid nodules, there was no significant 
Table 2. Correlation of CT-detected calcification patterns with the thyroid nodular nature

\begin{tabular}{|c|c|c|c|c|}
\hline Items & Malignant (n, \%) & Benign (n, \%) & $x^{2}$ & $P$ \\
\hline Calcification & & & 83.31 & $<0.01$ \\
\hline Positive & $88(52.38 \%)$ & $143(18.77 \%)$ & & \\
\hline Negative & $80(47.62 \%)$ & $619(81.23 \%)$ & & \\
\hline Calcification size & & & 1.05 & 0.31 \\
\hline Microcalcification & $45(51.14 \%)$ & $83(58.04 \%)$ & & \\
\hline Coarse & $43(48.86 \%)$ & $60(41.96 \%)$ & & \\
\hline Calcification numbers & & & 0.55 & 0.46 \\
\hline Solitary & $53(60.23 \%)$ & $79(55.24 \%)$ & & \\
\hline Multiple & $35(39.77 \%)$ & $64(44.76 \%)$ & & \\
\hline Calcification distribution & & & 41.30 & $<0.01$ \\
\hline Intranodular & $70(79.55 \%)$ & $56(36.60 \%)$ & & \\
\hline Peripheral & $18(20.45 \%)$ & $97(63.40 \%)$ & & \\
\hline
\end{tabular}

Table 3. Incidence of microcalcification and coarse calcification in patients with various malignant thyroid nodules

\begin{tabular}{lccccc}
\hline & $n$ & $\begin{array}{c}\text { Coarse calcification } \\
(>2 \mathrm{~mm})\end{array}$ & $\begin{array}{c}\text { Microcalcification } \\
(\leq 2 \mathrm{~mm})\end{array}$ & Calcification rate $(\%)$ & $\chi^{2}$ \\
\hline Papillary carcinoma & 91 & 27 & 27 & 59.34 & \\
Medullary carcinoma & 6 & 1 & 3 & 66.67 & 3.815 \\
Follicular carcinoma & 7 & 2 & 0 & 28.57 & 0.258 \\
Microcarcinoma & 63 & 17 & 10 & 42.86 & \\
\hline Total & 167 & 47 & 40 & 52.10 & \\
\hline
\end{tabular}

Fisher's exact test.

Table 4. Comparison of the calcification rate between males and females in malignant and benign thyroid nodules

\begin{tabular}{lccccc}
\hline & \multicolumn{2}{c}{ Malignant $(\mathrm{n}, \%)$} & & \multicolumn{2}{c}{ Benign $(\mathrm{n}, \%)$} \\
\cline { 2 - 3 } \cline { 5 - 6 } Items & $\begin{array}{c}\text { Calcification } \\
(\mathrm{n}=80)\end{array}$ & $\begin{array}{c}\text { Non-calcification } \\
(\mathrm{n}=88)\end{array}$ & & $\begin{array}{c}\text { Calcification } \\
(\mathrm{n}=143)\end{array}$ & $\begin{array}{c}\text { Non-calcification } \\
(\mathrm{n}=619)\end{array}$ \\
\hline Male & $18(46.15 \%)$ & $21(53.85 \%)$ & $29(15.93 \%)$ & $153(84.07 \%)$ \\
Female & $72(55.81 \%)$ & $57(44.19 \%)$ & & $114(19.66 \%)$ & $466(80.34 \%)$ \\
\hline P-value & & 0.26 & & & 0.29 \\
\hline
\end{tabular}

difference in the incidence of calcification between males and females $(P>0.05)$ (Table 4$)$. The mean age of male patients with malignant thyroid nodules was significantly lower than of those with benign nodules $(49.12 \pm 12.31$ vs $53.86 \pm 11.72$, $P<0.05)$. However, the mean age did not differ significantly between female patients with malignant and benign thyroid nodules $(51.18 \pm 12.80$ vs $52.12 \pm 13.71, P=0.539)$.

\section{Discussion}

It is critically important to distinguish malignancy when facing thyroid nodules in clinical practice. Both malignant and benign thyroid nodules can develop calcifications, with higher incidence of calcification detected in malignant nodules (42\%-72.3\%) compared with that in benign nodules (13.1\%-23.0\%) [5-7]. At present, the major preoperative tool for diagnosing thyroid lesions is ultrasonography, be- cause this method is relatively inexpensive, sensitive and easy-operating [8]. In contrast to ultrasonography, CT is uncommon in clinical practice due to high expense, more radiation exposure and doubtful utility in private clinical practice. However, CT could give additional information for restrosternal goiters, cervical metastatic illness, and so on, which may be useful in guiding further operation planning preoperatively. According to our experience, there is a united standard for the diagnosis of calcification on CT, while the diagnosis of calcification on ultrasonography depends on the senior doctors' experience to a great extent. In addition, calcification is also a common finding in thyroid nodules on CT, suggesting that CT-detected calcified thyroid nodules may have the potential value for predicting possible malignancy in thyroid nodules. This study found that CTdetected calcification, especially intranodular calcification, is associated with thyroid carcinoma (Table 2). 
At ultrasonography, the reported incidence rate of calcification in thyroid nodules was $37.75 \%$ [9]. Wu et al have reported that the rate of calcification in thyroid nodules observed on CT was $35 \%$ [7]. In our study, the results showed that calcification was noted in $24.84 \%$ of the thyroid nodules, which was lower than the above results. The possible reason may be that ultrasonography has a higher detecting ability of calcifications $<1$ $\mathrm{mm}$ than $\mathrm{CT}$ and the different technical setting or types of CT machines compared with the study of Wu et al [7]. Besides, our study included a larger population than that in the study of $\mathrm{Wu}$ et al [7]. Previous studies have demonstrated that the incidence of calcification in malignant thyroid nodules is higher than that in benign thyroid nodules whatever on ultrasonography or CT [7, 10-12]. Similar to the above results, it was found in our study that the incidence of calcification was significantly higher in patients with malignant nodules than those with benign nodules $(P<0.01)$ (Table 2$)$.

It has been found that microcalcification is associated with thyroid carcinoma and coarse calcification is associated with benign nodules [7, 13-15]. Microcalcification indicates the histological pattern of "psammoma bodies" [16], which are typically found in thyroid papillary carcinomas. However, ultrasonography-detected microcalcification and the associated psammoma bodies do not cover the several calcification types found histologically $[17,18]$. The reported microcalcification incidence ranged from $29.0 \%$ to $38.2 \%$ in malignant thyroid nodules with calcification $[3,19]$. On CT, Wu et al also reported a strong correlation of micro-calcification with malignant thyroid nodules [7]. In this study, the microcalcification incidence rate was $51.14 \%$ in malignant nodules and no significant difference in the size of calcification was found between malignant and benign thyroid nodules. Most of the previous studies used ultrasonography to investigate the size of calcification (Table 2). The possible reasons were listed as follows. Most of the previous studies used ultrasonography to investigate the size of calcification, and ultrasonography has a higher detecting ability of calcifications $<1 \mathrm{~mm}$ than CT. In addition, we also found calcification by pathological examination in 10 cases of thyroid carcinoma, but the preoperative CT was negative. This also indicates the suboptimal detection of microcalcification by CT.

It has been shown that ultrasonography-detected intranodular calcification suggests malignant thyroid nodules while peripheral calcification suggests benign thyroid nodules [2]. We found similar results with CT detection of thyroid nodule calcification. It was found that $79.55 \%$ of the intra-nodular calcification was associated with malignancy, and significant correlation was found between CT-detected intra-calcification and malignant thyroid nodules (Table 2). Besides, some studies have shown that the solitary calcified thyroid nodule is associated with malignancy both on ultrasonography and CT imaging $[7,12,20]$. However, our results showed no significant correlation of solitary calcified thyroid nodule with the incidence of malignancy (Table 2). The specific mechanisms underlining the different calcification patterns between ma- lignant and benign thyroid nodules remain unclear. Further investigation is needed to elucidate problem.

In addition to calcification, there are several other imaging features for the differentiation of benign and malignant thyroid nodules. Malignant nodules can demonstrate ultrasonography features such as taller than wide, spiculated margin, and hypoechogenicity, which have an overall sensitivity of $83.3 \%$ and specificity of $74.0 \%$ [6]. While benign nodules show ultrasonography features of isoechogenicity and spongiform appearance, with sensitivity of $56.6 \%$ and $10.4 \%$ and specificity of $88.1 \%$ and $99.7 \%$, respectively.

Moon et al analyzed 1083 thyroid nodules and found that central flow is the most common distinction between benign and malignant nodules [21]. Of the 1083 nodules studied, 814 were benign and 269 were malignant. Intranodular vascularity was frequently observed in the benign nodules, and vascularity was more often absent in the malignant nodules. Baier et al evaluated the ultrasonography and the clinical and laboratory characteristics of 944 patients with thyroid nodules and noted an association between malignant solid nodules and patient age younger than 45 years [22]. In contrast, Choi et al found no association between age and malignancy in nodules with indeterminate cytology [23]. The authors studied the cases of 165 patients who had been diagnosed with follicular tumors and found no significant associations between malignancy and sex, age, diameter, or ultrasonography characteristics, although there was a significant association with central flow by Doppler study. We also found no association between sex and thyroid malignancy (Table 4).

Our study has some limitations, of which we are aware. This study was a retrospective study, which was limited by the nature of retrospective study itself with selection bias. On the another hand, micro-calcification of some patients may be neglected because 3- to 5- mm slice thickness of CT images was used, which may affect our results in some extent. The technical details should be improved in the future study.

In conclusion, this study found that CT-detected calcification, especially intranodular calcification, may suggest an increased risk of thyroid carcinoma. However, the sensitivity and specificity of these two diagnostic parameters are not high enough. Fine-needle aspiration or surgical pathological examination is still needed to confirm the suspected thyroid malignancies.

Acknowledgements: This work was supported by a grant from Medical Imaging Center of Shanghai Changning District (2004qzx01). We have no conflict of interest to state.

\section{References}

[1] CHEN G, ZHU XQ, ZOU X, YAO J, LIANG JX, et al. Retrospective analysis of thyroid nodules by clinical and pathological characteristics, and ultrasonographically detected calcification correlated to thyroid carcinoma in South China. Eur Surg Res 2009; 42: 137-142. http://dx.doi. org/10.1159/000196506 
[2] KIM BK, CHOI YS, KWON HJ, LEE JS, HEO JJ, et al. Relationship between patterns of calcification in thyroid nodules and histopathologic findings. Endocr J 2013; 60: 155-160. http://dx.doi.org/10.1507/endocrj.EJ12-0294

[3] TAKI S, TERAHATA S, YAMASHITA R, KINUYA K, NOBATA K, et al. Thyroid calcifications: sonographic patterns and incidence of cancer. Clin Imaging 2004; 28: 368-371. http:// dx.doi.org/10.1016/S0899-7071(03)00190-6

[4] CHAMMAS MC, DE ARAUJO FILHO VJ, MOYSES RA, BRESCIA MD, MULATTI GC, et al. Predictive value for malignancy in the finding of microcalcifications on ultrasonography of thyroid nodules. Head Neck 2008; 30: 1206-1210. http://dx.doi.org/10.1002/hed.20858

[5] FUKATSU H, MAKINO N, KODAMA Y, IKEDA M, ISHIGAKI T, et al. Evaluation of thyroid calcification using computed radiography with image plate. Eur J Radiol 1989; 9: 22-28.

[6] MOON WJ, JUNG SL, LEE JH, NA DG, BAEK JH, et al. Benign and malignant thyroid nodules: US differentiation-multicenter retrospective study. Radiology 2008; 247: 762-770. http://dx.doi.org/10.1148/radiol.2473070944

[7] WU C-W, DIONIGI G, LEE K-W, HSIAO P-J, PAUL SHIN $\mathrm{M}-\mathrm{C}$, et al. Calcifications in thyroid nodules identified on preoperative computed tomography: Patterns and clinical significance. Surgery 2012; 151: 464-470. http://dx.doi. org/10.1016/j.surg.2011.07.032

[8] DEAN DS, GHARIB H. Epidemiology of thyroid nodules. Best Pract Res Clin Endocrinol Metab 2008; 22: 901-911. http://dx.doi.org/10.1016/j.beem.2008.09.019

[9] TAKI S, TERAHATA S, YAMASHITA R, KINUYA K, NOBATA K, et al. Thyroid calcifications: sonographic patterns and incidence of cancer. Clin Imaging 2004; 28: 368-371. http:// dx.doi.org/10.1016/S0899-7071(03)00190-6

[10] SEIBERLING KA, DUTRA JC, GRANT T, BAJRAMOVIC S. Role of intrathyroidal calcifications detected on ultrasound as a marker of malignancy. The Laryngoscope 2004; 114: 1753-1757. http://dx.doi.org/10.1097/00005537-200410000$\underline{00014}$

[11] KOIKE E, NOGUCHI S, YAMASHITA H, MURAKAMI T, OHSHIMA A, et al. Ultrasonographic characteristics of thyroid nodules: prediction of malignancy. Arch Surg 2001; 136: 334-337. http://dx.doi.org/10.1001/ archsurg.136.3.334

[12] KAKKOS SK, SCOPA CD, CHALMOUKIS AK, KARACHALIOS DA, SPILIOTIS JD, et al. Relative risk of cancer in sonographically detected thyroid nodules with calcifications. J Clin Ultrasound 2000; 28: 347-352. http://
dx.doi.org/10.1002/1097-0096(200009)28:7<347::AIDLCU5>3.0.CO;2-O

[13] WANG Z, ZHANG H, ZHANG P, HE L, DONG W. Diagnostic Value of Ultrasound-detected Calcification in Thyroid Nodules. Ann Acad Med Singapore 2014; 43: 102-106.

[14] ZHU LC, YE YL, LUO WH, SU M, WEI HP, et al. A model to discriminate malignant from benign thyroid nodules using artificial neural network. PloS one 2013; 8: e82211. http:// dx.doi.org/10.1371/journal.pone.0082211

[15] MA JJ, DING H, XU BH, XU C, SONG LJ, et al. Diagnostic performances of various gray-scale, color Doppler, and contrast-enhanced ultrasonography findings in predicting malignant thyroid nodules. Thyroid 2014; $24: 355-363$. http:// dx.doi.org/10.1089/thy.2013.0150

[16] TAKASHIMA S, FUKUDA H, NOMURA N, KISHIMOTO H, KIM T, et al. Thyroid nodules: re-evaluation with ultrasound. J Clin Ultrasound 1995; 23: 179-184. http://dx.doi. org/10.1002/jcu.1870230306

[17] BAI Y, ZHOU G, NAKAMURA M, OZAKI T, MORI I, et al. Survival impact of psammoma body, stromal calcification, and bone formation in papillary thyroid carcinoma. Mod Pathol 2009; 22: 887-894. http://dx.doi.org/10.1038/ modpathol.2009.38

[18] DAS DK, MALLIK MK, HAJI BE, AHMED MS, ALSHAMA'A M, et al. Psammoma body and its precursors in papillary thyroid carcinoma: a study by fine-needle aspiration cytology. Diagn Cytopathol 2004; 31: 380-386. http://dx.doi. org/10.1002/dc.20124

[19] WANG N, XU Y, GE C, GUO R, GUO K. Association of sonographically detected calcification with thyroid carcinoma. Head Neck 2006; 28: 1077-1083. http://dx.doi.org/10.1002/ $\underline{\text { hed.20481 }}$

[20] KHOO ML, ASA SL, WITTERICK IJ, FREEMAN JL. Thyroid calcification and its association with thyroid carcinoma. Head Neck 2002; 24: 651-655. http://dx.doi.org/10.1002/ $\underline{\text { hed. } 10115}$

[21] MOON HJ, KWAK JY, KIM MJ, SON EJ, KIM EK. Can vascularity at power Doppler US help predict thyroid malignancy? Radiology 2010; 255: 260-269. http://dx.doi.org/10.1148/ radiol.09091284

[22] BAIER ND, HAHN PF, GERVAIS DA, SAMIR A, HALPERN EF, et al. Fine-needle aspiration biopsy of thyroid nodules: experience in a cohort of 944 patients. AJR Am J Roentgenol 2009; 193: 1175-1179. http://dx.doi.org/10.2214/AJR.08.1840

[23] CHOI YJ, YUN JS, KIM DH. Clinical and ultrasound features of cytology diagnosed follicular neoplasm. Endocr J 2009; 56: 383-389. http://dx.doi.org/10.1507/endocrj.K08E-310 